\title{
Single injection thoracic paravertebral block (TPVB) for breast surgery in morbidly obese patient
}

\begin{abstract}
Morbidly obese (MO) patients with associated restrictive airway disease, obstructive sleep apnea, and coronary artery disease pose challenge to an anesthesiologist. Regional block combined with general anesthesia (GA) is the anesthetic technique of choice as it will decrease the requirement of opioids, anesthetics, and postoperative respiratory depression. A MO patient for modified radical mastectomy was successfully managed with single-injection thoracic paravertebral block and conventional GA.
\end{abstract}

Keywords: Breast surgery, morbid obesity, thoracic paravertebral block

\section{INTRODUCTION}

Morbidly Obese patient pose challenge to the anesthesiologist regarding difficult airway,delayed recovery and need for postoperative assisted ventilation. We present anesthesia management of morbidly obese patient for radical mastectomy performed under thoracic paravertebral block as adjuvant to General anaesthesia successfully.

\section{CASE REPORT}

A 53-year-old female, weight $140 \mathrm{~kg}$, height $168 \mathrm{~cm}$, body mass index (BMI) $49.60 \mathrm{~kg} / \mathrm{m}^{2}$, was posted for left modified radical mastectomy.

Preoperative evaluation revealed that her weight gain was dietary in origin. The patient was hypertensive for 10 years receiving tablet Amtas E 1OD. She gave no history suggestive of obstructive sleep apnea (OSA), coronary artery disease (CAD), diabetes mellitus (DM), thyroid dysfunction. The patient had no contraindication to paravertebral block (PVB) as local sepsis, allergy to local anesthetics, coagulopathy, or severe respiratory disease.

On general examination, her pulse rate was $96 / \mathrm{min}$, blood pressure (BP) was 160/104 mmHg, airway evaluation revealed

\begin{tabular}{|l|c|}
\hline \multicolumn{2}{|c|}{ Access this article online } \\
\hline \multirow{2}{*}{$\begin{array}{l}\text { Website: } \\
\text { www.asjo.in }\end{array}$} & Quick Response Code \\
\cline { 2 - 2 } & \\
DOI: & \\
10.4103/ASJO.ASJO_81_15 & \\
&
\end{tabular}

Mallampati Grade II, and neck circumference was $42.5 \mathrm{~cm}$. Residual stress and cardiovascular (CVS) examination were normal.

Routine hematological, biochemistry investigations including thyroid function test were within normal limits. X-ray of the chest and electrocardiogram (ECG) were normal. Two-dimensional echocardiography showed left ventricular ejection fraction - $61 \%$, no regional wall motion abnormality, and LV diastolic dysfunction Grade I. Pulmonary function test was suggestive of moderate restrictive pulmonary function. Arterial blood gas (ABG) on room air revealed $\mathrm{PaO}_{2}-62.0 \mathrm{mmHg}, \mathrm{PaCO}_{2}-41.9 \mathrm{mmHg}, \mathrm{pH}-7.43$, and $\mathrm{O}_{2}$ saturation $\left(\mathrm{SpO}_{2}\right)-92.3 \mathrm{mmHg}$.

Premedication included antihypertensive drugs on the day of surgery. Tablet ondansetron $16 \mathrm{mg}$ and tablet

\section{Anita Kulkarni, Vedapadmapriya Selvakumar, NAMrata Gupta ${ }^{1}$ \\ Rajiv Gandhi Cancer Institute and Research Centre, New Delhi, ${ }^{1}$ Department of Anesthesiology, Narayana Hrudayalaya Hospital, Bengaluru, Karnataka, India \\ Address for correspondence: Dr. Anita Kulkarni, C701, KM Apartments, Plot No 12, Sector 12, Dwarka, New Delhi - 110 078, India. \\ E-mail: anitackulkarni@gmail.com}

This is an open access article distributed under the terms of the Creative Commons Attribution-NonCommercial-ShareAlike 3.0 License, which allows others to remix, tweak, and build upon the work non-commercially, as long as the author is credited and the new creations are licensed under the identical terms.

For reprints contact: reprints@medknow.com

How to cite this article: Kulkarni A, Selvakumar V, Gupta N. Single injection thoracic paravertebral block (TPVB) for breast surgery in morbidly obese patient. Asian J Oncol 2017;3:96-9. 
ranitidine $150 \mathrm{mg}$ were given $1 \mathrm{~h}$ before the surgery. No oral benzodiazepines were given.

In the operation theater, her heart rate was $76 / \mathrm{min}$, BP was $143 / 81 \mathrm{mmHg}$, intravenous (IV) access gained with 18-gauge cannula on the nonoperative arm.

Monitoring included 5-lead ECG, noninvasive blood pressure (large-sized cuff), $\mathrm{SpO}_{2}$, end-tidal $\mathrm{CO}_{2}\left(\mathrm{ETCO}_{2}\right)$, spirometry, peripheral nervous system (ulnar nerve) using Datex Ohmeda monitor.

In sitting position, ipsilateral left PVB was given at T3 level $3 \mathrm{~cm}$ lateral from the cephalad edge of spinal process; the skin, subcutaneous tissue, and periosteum of the transverse process (TP) were anesthetized with $2.5 \mathrm{ml}$ of lidocaine $10 \mathrm{mg} / \mathrm{ml}$. Initially, TP was identified with 21 -gauge hypodermic needle as shown in Figure 1 and distance to reach TP was noted; then, the PVB was performed with 22-gauge spinal needle, seeking contact with the lateral process of the T3 vertebrae as a landmark before advancing the needle caudally few millimeters into the paravertebral space using loss of resistance technique [Figure 2]; bupivacaine $0.2 \mathrm{ml} / \mathrm{kg}$ lean body weight $(1 \mathrm{ml}=5 \mathrm{mg})$ was injected into the paravertebral space in small aliquots with repeated aspiration tests. Paravertebral space was located at a depth of $4.7 \mathrm{~cm}$. T1-T6 dermatome block was achieved in $15 \mathrm{~min}$, demonstrated with decreased sensation to pinprick. No complication such as intrapleural block or pneumothorax was encountered. For optimization of intubating position, sheets were kept below both the scapulae. The patient was preoxygenated with $100 \%$ oxygen for 3 min. Induction was achieved with midazolam $1 \mathrm{mg}$, fentanyl $1 \mu \mathrm{g} / \mathrm{kg}$, propofol $1 \mathrm{mg} / \mathrm{kg}$, atracurium $0.5 \mathrm{mg} / \mathrm{kg}$. The trachea was intubated nasally with prewarmed Portex endotracheal tube (ETT) (ID

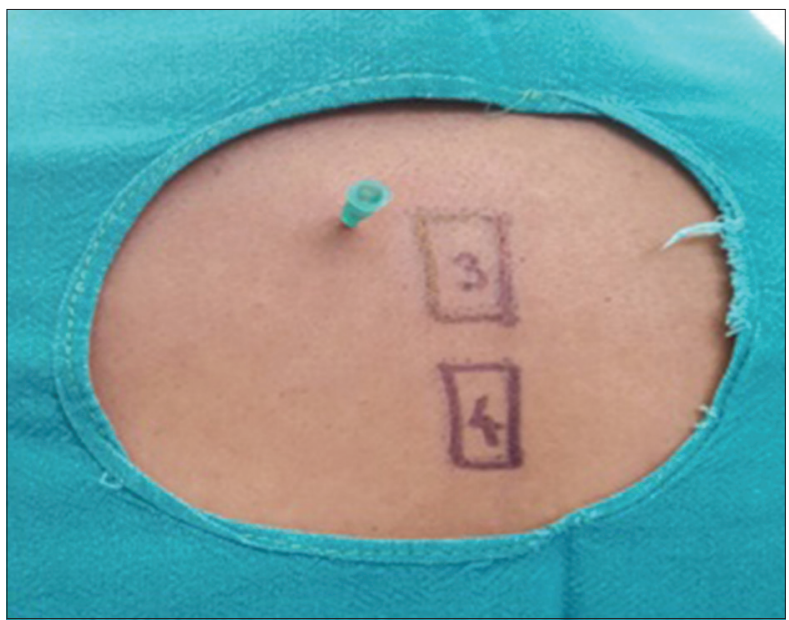

Figure 1: Hypodermic 21-gauge needle seen lateral to T3 vertebrae to identify transverse process
$7.0 \mathrm{~mm}$ ) in the first attempt, tube placement confirmed with capnography, and laryngoscopy revealed Cormack-Lehane Grade II.

Anesthesia was maintained with $\mathrm{O}_{2} / \mathrm{N}_{2} \mathrm{O} 40 \%-60 \%$, sevoflurane $1.5 \%-2 \%$, intermittent positive pressure ventilation (IPPV), volume-controlled mode with tidal volume $6-8 \mathrm{ml} / \mathrm{kg} / \mathrm{min}$, respiratory rate $11 / \mathrm{min}$, positive end-expiratory pressure (PEEP) $8 \mathrm{~cm} \mathrm{H} \mathrm{H}_{2} \mathrm{O}$. Maximum paw reached was $32 \mathrm{mmHg}$. $\mathrm{ETCO}_{2}$ was maintained between 30 and $34 \mathrm{mmHg}, \mathrm{SpO}_{2}$ ranged 95\%-97\%. During the surgery, the patient was hemodynamically stable. Duration of surgery was $150 \mathrm{~min}$. At the end of surgery, neuromuscular block was reversed with IV neostigmine $3.5 \mathrm{mg}$ and glycopyrrolate $0.5 \mathrm{mg}$.

Emergence was smooth with the patient awake, breathing adequate tidal volume spontaneously, and pain-free. She was shifted to the postanesthesia care unit, nasal ETT in situ, receiving oxygen through T-piece. The trachea was extubated after $16 \mathrm{~h}$. The patient had uneventful recovery.

Postoperative analgesia was managed with preoperative PVB injection diclofenac sodium $75 \mathrm{mg} / 8$ hourly and IV morphine $3 \mathrm{mg}$ as per the requirement if pain score was more than 3 . Total morphine required in $24 \mathrm{~h}$ was $6 \mathrm{mg}$.

\section{DISCUSSION}

Morbid obesity (MO) is defined as $\mathrm{BMI}>31 \mathrm{~kg} / \mathrm{m}^{2}$. MO is associated with CVS and respiratory comorbidities such as $\mathrm{CAD}$, restrictive airway disease, DM, and atherosclerosis. These patients have higher incidence of difficult tracheal intubation; the expiratory reserve volume and functional residual capacity (FRC) are reduced $60 \%-80 \% .^{11}$

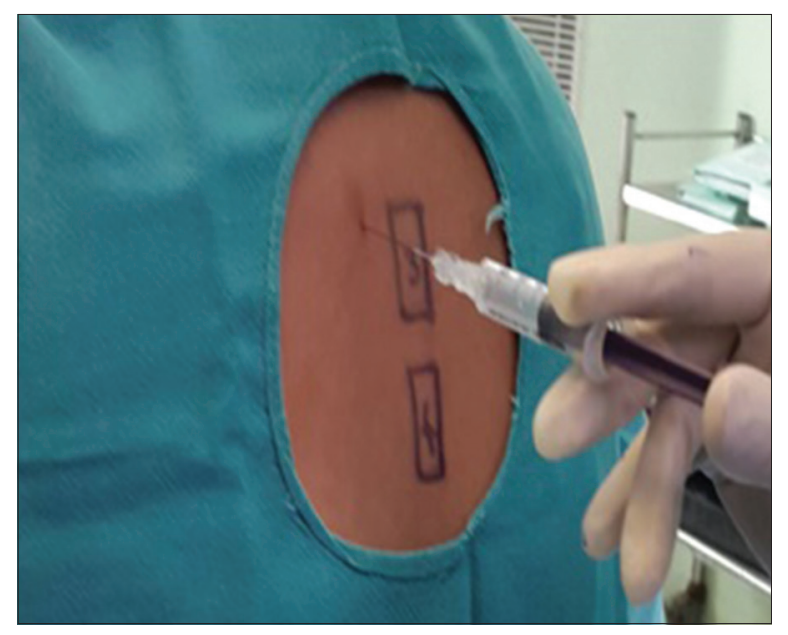

Figure 2: Thoracic paravertebral block given with 22-gauge spinal needle with loss of resistance technique 
Fifty percent of MO patients have moderate to severe OSA. Prevalence of OSA in MO women is 3\%-25\%. Our patient had BMI $>40 \mathrm{~kg} / \mathrm{m}^{2}$, neck circumference was $>40 \mathrm{~cm}$, and room air $\mathrm{ABG}$ revealed $\mathrm{PaO}_{2}<65 \mathrm{mmHg}$ and $\mathrm{PaCO}_{2}>45 \mathrm{mmHg}$. Hence, she was considered patient with moderate OSA.

Anesthesia concerns in MO patients are rapid desaturation during induction of anesthesia as FRC is decreased due to restricted diaphragmatic excursions. A high Mallampati score and large neck circumference increase the risk of difficult laryngoscopy and tracheal intubation..$^{[2]}$

Airway assessment of our patient revealed Mallampati Grade II optimization of intubating position was achieved by keeping sheets below both the scapulae and preoxygenation with $100 \%$ oxygen for 3 min was performed to prevent desaturation during induction. Mask ventilation was not difficult.

Nasotracheal intubation was achieved successfully in the first attempt with Macintosh laryngoscope (difficult airway cart was kept available). Nasal ETT was placed as it is better tolerated by the patient postoperatively to maintain airway patency in view of OSA.

Intraoperatively, maintenance of anesthesia was achieved with $\mathrm{O}_{2} / \mathrm{N}_{2} \mathrm{O}$ sevoflurane minimum alveolar concentration $2 \%$, intermittent bolus of fentanyl, and atracurium. Short-acting agents were preferred to achieve rapid emergence. IPPV with tidal volume was $8-10 \mathrm{ml} / \mathrm{min}$ and PEEP $8 \mathrm{~cm} \mathrm{H}_{2} \mathrm{O} . \mathrm{ETCO}_{2}$ was maintained between 30 and $34 \mathrm{mmHg}$, and paw was between 26 and $32 \mathrm{mmHg}$. Application of PEEP during induction and before the development of atelectasis improves oxygenation in MO patients..$^{[2]}$

Successful single shot thoracic PVB (TPVB) significantly decreased opioid requirement of our patient during surgery, thus decreasing postoperative respiratory depression; hence, use of short-acting opioids and regional techniques is desirable.

Regional technique

Single-injection TPVB at T3 or T4 is appropriate for mastectomy ${ }^{[3]}$ with a 22-gauge spinal needle, Anatomical landmark method and loss of resistance technique was used to identify paravertebral space .Single injection TPVB was given at T3 for mastectomy surgery with $22 \mathrm{G}$ spinal needle, and $0.2 \mathrm{ml} / \mathrm{kg} 0.5 \%$ bupivacaine was injected. T2T6 dermatome block was achieved..$^{[4]}$ During the surgery, requirement of opioids was considerably decreased, and total IV $4.5 \mathrm{mg}$ morphine and $80 \mu \mathrm{g}$ fentanyl were required.
Postoperative pain was managed with TPVB and nonsteroidal anti-inflammatory drug. It has been reported that patients receiving single-injection PVB at T3 with bupivacaine $1.5 \mathrm{mg} /$ $\mathrm{kg}$ require $40 \%$ less IV opioids in the postoperative period and incidence of postoperative nausea and vomiting is also decreased. There is evidence of vertical spread of the paravertebrally injected local anesthetic over several adjacent dermatomes. Cheema et al. noted a unilateral spread of sensory analgesia from one to eight dermatomes after a single injection of $15 \mathrm{ml} 0.5 \%$ bupivacaine for TPVB. ${ }^{[5]}$ Advantages of PVB are easy to perform and analgesia is intense and prolonged, less risk of neurological complications, and profound hypotension because of sympathetic block as with central neuraxial blockade. There is less sedation, nausea, and vomiting as requirement of opioids is reduced. ${ }^{[6]}$

Postoperatively, to maintain airway patency, nasal ETT was retained at the end of surgery as high suspicion of OSA existed. The patient was breathing spontaneously receiving oxygenation through $\mathrm{T}$-piece. She maintained $\mathrm{SpO}_{2}>95 \mathrm{mmHg}$. The trachea was extubated after $16 \mathrm{~h}$, and she had an uneventful recovery.

\section{CONCLUSION}

Single-injection TPVB as adjuvant to general anesthesia decreases the requirement of perioperative opioids thus ensures rapid emergence from anesthesia and reduced postoperative respiratory depression. ${ }^{[7]}$ PVBs have been shown to reduce chronic pain after breast surgery probably by preventing sensitization of the central nervous system and $\mathrm{N}$-methyl D-aspartate receptor wind up. The meta-analysis found evidence on the efficacy and safety of PVB to provide anesthesia and postoperative analgesia during breast surgery with little adverse events. ${ }^{[8]}$

Hence, we recommend TPVB as adjuvant to general anesthesia for MO patients undergoing breast surgery.

\section{Financial support and sponsorship}

Nil.

\section{Conflicts of interest}

There are no conflicts of interest.

\section{REFERENCES}

1. Roizen MF, Fleisher LA. Anesthetic implications of concurrent disease. In: Miller RD, editor. Miller's Anesthesia. $7^{\text {th }}$ ed. Philadelphia, PA: Churchill Livingstone Elsevier; 2010. p. 1077.

2. Sprung J. Perioperative respiratory strategies for morbidly obese patients. Am Soc Anesthesiol Newsl 2005;69:32-3. 
3. Tighe SQ, Greene MD, Rajadurai N. Paravertebral block. Contin Educ Anesth Crit Care Pain 2010;10:133-7.

4. Kairaluoma PM, Bachmann MS, Korpinen AK, Rosenberg PH, Pere PJ. Single-injection paravertebral block before general anesthesia enhances analgesia after breast cancer surgery with and without associated lymph node biopsy. Anesth Analg 2004;99:1837-43.

5. Cheema SP, Ilsley D, Richardson J, Sabanathan S. A thermographic study of paravertebral analgesia. Anaesthesia 1995;50:118-21.
6. Pusch F, Freitag H, Weinstabl C, Obwegeser R, Huber E, Wildling E. Single-injection paravertebral block compared to general anaesthesia in breast surgery. Acta Anaesthesiol Scand 1999;43:770-4.

7. Klein SM, Bergh A, Steele SM, Georgiade GS, Greengrass RA. Thoracic paravertebral block for breast surgery. Anesth Analg 2000;90:1402-5.

8. Schnabel A, Reichl SU, Kranke P, Pogatzki-Zahn EM, Zahn PK. Efficacy and safety of paravertebral blocks in breast surgery: A meta-analysis of randomized controlled trials. Br J Anaesth 2010;105:842-52. 